\title{
PARADOJAS DE LA ENERGÍA EÓLICA ¿ALTERNATIVA AL CAMBIO CLIMÁTICO EN LA AGENDA GLOBAL? EL CORREDOR EÓLICO EN EL ISTMO DE TEHUANTEPEC, OAXACA, MÉXICO
}

\author{
Paradoxes of Energy Eolic. Alternative to Climate Change \\ In the Global Agenda? The Wind Corridor in the Isthmus \\ Of Tehuantepec, Oaxaca, Mexico
}

\author{
OCTAVIO ALONSO SOLÓRZANO-TELLO1, TERESA DE JESÚS PORTADOR-GARCÍA² \\ ${ }^{1}$ Benemérita Universidad Autónoma de Puebla (BUAP/México). \\ 2 Universidad Autónoma Metropolitana Iztapalapa (UAM-I/México).
}

\section{E-mail: telloctavio@yahoo.com.mx}

tportadorgarcia@yahoo.com

Recibido: 30 de Septiembre de 2016

Aceptado: 16 de Noviembre de 2016

\section{Resumen}

Históricamente, la región del Istmo de Tehuantepec ubicada en el estado de Oaxaca, México ha sido blanco de grandes proyectos de desarrollo. A finales del siglo XIX (durante el gobierno de Porfirio Díaz) la construcción del ferrocarril originó cambios significativos, como la fundación de pueblos, la creación de nuevas rutas y vínculos comerciales interregionales y mundiales. En el siglo XX se idearon planes de infraestructura vial, carretera y portuaria, se incentivó la industria petrolera, se introdujeron cultivos comerciales para exportación y se propusieron megaproyectos como el Alfa Omega y el Plan Puebla Panamá que no se materializaron. A partir del siglo XXI una nueva configuración socioterritorial se ha ido consolidando por el arribo de empresas transnacionales productoras de energía eólica. El corredor eólico en el Istmo oaxaqueño fue el primero que se construyó en América Latina, de ahí la pertinencia de abordarlo como tema de análisis, no sólo por la importancia internacional que reviste, sino por las transformaciones sociales, políticas, territoriales y ambientales que está produciendo. El proyecto está enmarcado en el contexto de las políticas neoliberales que se han implementado a lo largo y ancho del continente desde la década de los ochenta; aunque al mismo tiempo responde al calentamiento global y a la crisis energética mundial, temas centrales en la agenda global. El artículo aborda las problemáticas surgidas a partir del arribo de las empresas que explotan los recursos naturales para producir energía; así como las estrategias políticas utilizadas por los pueblos indígenas zapotecos y huaves centrados en contrarrestar los impactos sociales, económicos, ambientales y agrarios que generan los proyectos eólicos.

Palabras claves: Crisis del medio ambiente, Empresas transnacionales, Indígenas, Neoliberalismo, Reconfiguración territorial.

\begin{abstract}
Historically, the region of the Isthmus of Tehuantepec located in the state of Oaxaca, Mexico has been the target of major development projects. At the end of the nineteenth century (during the Porfirio Diaz administration) the construction of the railroad led to significant changes, such as the founding of towns, the creation of new routes and interregional and world trade links. In the twentieth century, road, road and port infrastructure plans were designed, the oil industry was encouraged, commercial cash crops were introduced for export, and megaprojects such as the Alfa Omega and the Plan Puebla Panama were proposed that did not materialize. Starting from the 21st century, a new socio-territorial configuration has been consolidated by the arrival of transnational company producing wind energy. The wind corridor in the Oaxaca Isthmus was the first to be built in Latin America, hence the relevance of addressing it as a topic of analysis, not only because of its international importance, but also because of the social, political, territorial and environmental producing. The project is framed within the context of neoliberal policies that have been implemented throughout the continent since the 1980s; although at the same time responding to global warming and the global energy crisis, which are central to the global agenda. The article addresses the problems arising from the arrival of companies that exploit natural resources to produce energy; as well as the political strategies used by the zapotec and huaves indigenous peoples, focused on counteracting the social, economic, environmental and agricultural impacts generated by wind projects.
\end{abstract}

Keywords: Crisis of the environment, Transnational company, Indigenous, Neoliberalism, Territorial reconfiguration. 


\section{INTRODUCCIÓN}

La crisis energética y el calentamiento global son temas prioritarios en la agenda global sobre el Cambio Climático que inicia en la COP-1 (Conference of the Parties, por sus siglas en inglés) ${ }^{1}$ en 1995 en Berlín Alemania hasta la COP21 celebrada en París del 30 de noviembre al 11 de diciembre de 2015, integrada por 194 países entre ellos México. Espacios donde se han propuesto consolidar e implementar programas, proyectos y líneas de acción para reducir los Gases de Efecto Invernadero (GEI) en el siglo XXI. El discurso de las energías renovables y alternativas como mitigadoras del cambio climático se ha posicionado a nivel mundial. En este sentido, se ha planteado como indispensable apresurar el proceso de transición de energías fósiles hacia las renovables, como la eólica y la solar, crucial para afrontar la crisis energética y hacer frente a los GEI.

Los países de la Unión Europea y de América Latina coinciden que uno de los ejes que sustentan la relación y la cooperación mundial es el cambio climático, debido a que ya están padeciendo las externalidades negativas, provocando daños económicos, sociales y ambientales. De ahí que han impulsado iniciativas, acuerdos y agendas comunes que contribuyan a frenar el deterioro ambiental, cimentados en los objetivos de la Convención Marco de las Naciones Unidas sobre el Cambio Climático (CMNUCC) ${ }^{2}$ y del Protocolo de Kioto. ${ }^{3}$ Han enfatizado la necesidad de formular políticas y programas que tomen en cuenta no sólo lo ambiental, sino los aspectos sociales y económicos. De ahí que una de las líneas de acción propuestas por estos países sea la cooperación en materia de energía eólica, visualizando que las incidencias sean de mayor alcance.

Es así como los países europeos han penetrado en América Latina promoviendo, afianzando e invirtiendo en la implementación de parques eólicos, bajo el argumento de reforzar la relación y cooperación birregional a partir de lo que han denominado la transición hacia las energías limpias y renovables; y la transferencia de tecnología hacia los

\footnotetext{
1 La Conferencia de las Partes (COPs) es el órgano supremo de la Convención Marco de las Naciones Unidas sobre el Cambio Climático, y está conformada por representantes de los Estados miembros, agencias de las Naciones Unidas, organismos intergubernamentales y representantes de la sociedad civil.

2 La Convención entró en vigor en 1994 y desde entonces ha sido la encargada de construir marcos de acción para la estabilización de la concentración de gases de efecto invernadero en la atmósfera. Esta Convención procede a partir de las disposiciones y decisiones aportadas en las reuniones de la Conferencia de las Partes (COP) celebradas periódicamente en distintos países.

${ }^{3}$ El Protocolo entró en vigor el 16 de febrero de 2005 y lo conforman 39 países desarrollados. Es un instrumento multilateral que emanó de Naciones Unidas y busca que los países se comprometan a reducir las emisiones de gases de efecto invernadero.
}

países latinoamericanos, con el afán de contribuir al cumplimento de los compromisos planteados en la agenda global.

En el continente latinoamericano la implementación de proyectos eólicos ${ }^{4}$ tiene rostros similares y se apoya en el discurso del "desarrollo", de manera que cuentan con la anuencia de los gobiernos nacionales, originando expropiación de territorios y produciendo inconformidades en sectores de la sociedad. A partir de distintas acciones colectivas, los grupos sociales contrarrestan las tentativas de despojo territorial y las afectaciones, bajo el referente de procesos autonómicos, de organización comunitaria y de reapropiación del espacio.

Por lo anterior, este artículo abre la discusión y reflexión sobre el tema de la apropiación, el despojo y la defensa de los territorios y los recursos naturales que están generando las centrales eólicas en el Istmo de Tehuantepec ubicado en Oaxaca, México. La importancia de enfocar el análisis en estos proyectos radica en que fueron los primeros en América Latina, replicados después en países sudamericanos. En esta región istmeña, las transnacionales encontraron las condiciones climáticas, geográficas y políticas idóneas; grandes extensiones de tierras ejidales y facilidad para obtener los permisos de las autoridades municipales, estatales y federales sin revisiones escrupulosas de los impactos culturales, económicos y ambientales en las sociedades locales.

La información aquí mostrada es parte de la investigación in situ que iniciamos en el año 2004 y finalizamos en 2016. Los fenómenos y problemáticas que se desarrollan en el Istmo, nos exigieron múltiples miradas, por ello articulamos los enfoques histórico y etnográfico para una comprensión más integral.

En el primer apartado el lector encontrará una propuesta conceptual, útil para abordar y comprender las dinámicas generadas a partir de los megaproyectos transístmicos, hacemos uso de las categorías analíticas de territorio, espacio, actores colectivos y acción colectiva. En el segundo apartado abordamos la implementación de parques eólicos en el continente americano. Por último, describimos las formas en que se construyeron los parques eólicos en el Istmo, los procesos de negociación entre los habitantes, las

\footnotetext{
${ }^{4}$ La energía eólica se inspira en la fuerza del viento que mueve el molino o aerogenerador, y del sol que de manera complementaria genera los cambios de temperatura provocando corrientes de aire. Los aerogeneradores actualmente utilizan aspas de hasta 140 metros de largo cada una y son colocados sobre plataformas de cemento El escenario de los costos de producción de energía eólica es muy competitivo frente a otras fuentes y recursos energéticos.
} 
Ambiente y Sostenibilidad 2016 (6): 55-63

Revista del Doctorado Interinstitucional en Ciencias Ambientales

ISSN: 2339-3122

Digital

empresas y los gobiernos; así como las transformaciones y los efectos que se están generando a nivel social, agrario, ambiental y económico. Todo esto es nuestro punto de partida para el análisis de las estrategias y mecanismos que utilizan los actores colectivos para reapropiarse de sus territorios.

Propuesta conceptual para abordar el tema de las apropiaciones y reconfiguraciones territoriales en América Latina

Durante las últimas décadas, en América Latina se han incrementado los procesos de globalización neoliberal y con ello se han consolidado y profundizado políticas extractivistas emprendidas por empresas nacionales pero sobre todo transnacionales que apoyadas por distintos niveles de gobierno, han acelerado la implementación de megaproyectos, como las minerías a cielo abierto, los corredores eólicos, las presas, las hidroeléctricas, los gaseoductos, los parques turísticos, las unidades habitacionales, entre muchos otros. Dicha extracción y explotación de recursos naturales como el petróleo, el viento, el agua, los bosques, etcétera, han provocado la contaminación del agua, del suelo y de los mantos acuíferos, poniendo en peligro la biodiversidad del lugar y la vida misma de los habitantes. Como resultado de ello, los territorios se han transformado y reconfigurado a través del desplazamiento y la reubicación de poblaciones enteras.

La mayoría de estos proyectos justifican su pertinencia en la ideología del progreso y del desarrollo, cimientos discursivos del modelo económico neoliberal. El rechazo mostrado por algunos sectores de la sociedad civil, de pueblos y de comunidades rurales e indígenas (afectados directos de los impactos socioculturales, económicos, agrarios, y ambientales) se materializa en la articulación de movimientos sociales de alcance nacional e internacional. Estos mecanismos de organización sociopolítica presentan un amplio abanico de peticiones, pero las más frecuentes son la suspensión de proyectos y la elaboración de consultas para que los ciudadanos decidan si se implementan o no.

El rechazo civil a los megaproyectos, cuestionan hasta qué punto son verdaderos modelos de desarrollo encaminados a satisfacer genuinamente las necesidades de la población. Desde nuestro punto de vista la situación tiene otra lectura que permite plantear lo que denominamos la paradoja del desarrollo, es decir, estructuras de pensamientos heterogéneos que en determinados momentos y espacios se contraponen; los modelos de desarrollo implican dentro de sí mismos diversas y muchas veces contradictorias construcciones, concepciones y apropiaciones del espacio por parte de los actores implicados.

Marie-Dominique Perrot en su obra Les empêcheurs de développer en rond (1991) ubica al pensamiento desarrollista como un mito fundador del Occidente moderno. Para esta autora el desarrollo es un artefacto cultural que se construye en una temporalidad determinada de la historia de las naciones industrializadas. Afirma que este concepto tiene sus cimientos en el progreso económico, utilizado como eje rector de políticas gubernamentales y de megaproyectos. La perspectiva de Perrot nos permite proponer que ese pensamiento se convierte en una ideología, erigiéndose como dominante e imbricando ámbitos y niveles de la vida individual y colectiva ¿Qué sucede cuando ésta busca imponerse a otras colectividades? ¿Qué produce cuando se encuentra con otras lógicas de pensamiento y se impone como modelo de explotación y apropiación de territorios y de recursos naturales? Es un hecho que en estos contextos se establecen relaciones de poder, que son en sí mismas relaciones asimétricas. Por su parte, los proyectos eólicos en el Istmo de Tehuantepec nos permiten ejemplificar la paradoja del desarrollo, ya que en este espacio geográfico confluyen actores colectivos diferentes con sus respectivas concepciones y ocupaciones del territorio. En este caso hemos ubicado cuatro: 1) los habitantes locales, es decir, población indígena y mestiza; 2) las empresas transnacionales; 3) las Organizaciones No Gubernamentales (ONG's); y 4) los partidos políticos.

En este artículo, concebimos como actores colectivos a aquellos agentes facultados para tomar decisiones sobre un territorio. Tomamos en consideración las maneras en que ocupan, utilizan, transforman y defienden el espacio; las formas genuinas para imprimir su propia huella, definir los linderos físicos y simbólicos que contribuyen a su reproducción cultural e identitaria. Este enfoque nos ayuda a comprender la confluencia de diversos actores en un mismo territorio y las relaciones de poder que entre ellos se establecen.

Pero antes de abordar las concepciones que del espacio construye cada colectividad, es pertinente aclarar la diferencia con el territorio. Raffestin (1979) realiza un gran aporte al respecto, concibiendo al primero como un dato y al segundo como dato socializado; otorga relevancia a las representaciones y al sentido de territorio. Lo anterior nos remite a la noción del sujeto colectivo, en tanto son los actores quienes significan el espacio y en esa medida lo convierten en un territorio. Por su parte, Santos (2008) establece que el espacio debe ser considerado como un producto histórico debido a que los aspectos propios a cada población tienen influencia sobre la evolución espacial.

De esta manera, cada actor colectivo construye su propia 
concepción y representación del espacio, sus propios mecanismos de apropiación y de usos político, económico, social, cultural y simbólico. Hecho que necesariamente remite a la disputa por el control y la dominación de los recursos, puesto que precisamente cada actor les atribuye un valor diferente. Si retomamos la idea de Raffestin (1979), en cuanto a que los recursos son pretextos que originan prácticas y estrategias, entonces podemos plantear que para ciertos actores colectivos ambas se materializan en acciones conjuntas, como mecanismos para contraponerse a modelos dominantes de desarrollo.

Entonces presuponemos que para que se forje una acción colectiva deben existir ciertos componentes sociales como los objetivos y los problemas comunes, los agravios compartidos, los lazos de solidaridad, los mecanismos y las soluciones para enfrentar las problemáticas, y por supuesto los recursos en disputa. En el caso que estamos analizando, el motivo de la rivalidad es la apropiación de las tierras y los recursos naturales, es decir, el uso social y económico del territorio.

Es posible que en un mismo espacio confluyan distintas colectividades entablando relaciones de poder, Raffestin (1979) lo define como la existencia de múltiples poderes. La apropiación del espacio se realiza de forma concreta y abstracta, visibilizándose en las formas o maneras en que los actores territorializan el espacio. El concepto de infrapolítica propuesto por Scott (2000) también nos ayuda a entender dicha territorialización del espacio desde la insubordinación de los desvalidos, en tanto que los pueblos generan múltiples estrategias y resistencias, desde la acción directa y el uso de las leyes, hasta acciones simbólicas.

Las transnacionales son una clara muestra de cómo el poder económico se desdobla a esferas locales, regionales y nacionales, imponiendo la ideología del desarrollo, buscando obtener ganancias a partir de la explotación de los recursos naturales. Como bien lo apunta Raffestin (1979) el poder se encarna en el territorio.

Desde nuestro punto de vista, el poder tiene intersticios por donde se desliza el contrapoder, materializado en las oposiciones y rechazos a lógicas de producción e imposición de megaproyectos. Los pueblos indígenas zapotecos y huaves del Istmo de Tehuantepec han generado formas organizativas para detener el avance de dichos proyectos y aminorar los impactos en los distintos órdenes de su vida colectiva.

\section{Proyectos eólicos en América Latina}

América Latina está viviendo la expansión de proyectos de energía eólica y solar, debido a que en los últimos años, a nivel global ha ido ganando terreno el discurso de las "energías limpias" y renovables, que reducen el nivel de contaminantes emitidos a la atmósfera, en comparación con los combustibles fósiles, que elevan el nivel de emisiones de dióxido de carbono (CO2) al ambiente, provocando el efecto invernadero. La idea central de incentivar este tipo de energías es hacer frente al cambio climático.

Los proyectos eólicos están validados por el Mecanismo de Desarrollo Limpio (MDL), instrumento contemplado en el Protocolo de Kioto, que busca ayudar a los países, en la reducción de emisiones de gases de efecto invernadero. Las empresas transnacionales productoras de energías limpias se benefician de estos instrumentos al obtener ganancias adicionales y adquirir fondos mundiales ${ }^{5}$ para la inversión.

China, Estados Unidos y algunos países europeos están a la vanguardia en producción de energía eólica; en el continente americano, Brasil y México se han posicionado en los últimos años como los pioneros. Esto guarda relación con el aumento a nivel mundial de la demanda de energía, sobre todo las denominadas "limpias". Por su parte Chile, Argentina, Colombia, Ecuador, República Dominicana, Panamá, Nicaragua, Costa Rica se suman a la lista de países con capacidad de producción eólica, y en algunos ya están operando las centrales que producen este tipo de energía.

En el caso concreto de Brasil, desde el año 2002 se instauró un programa de estimulación de energía eólica y de otras fuentes renovables a partir del Programa de Incentivo de las Fuentes Alternativas de Energía Eléctrica. La empresa que acaparó la producción en la primera etapa 2002-2008 fue Wobben Enercon. Posteriormente participaron otros desarrolladores como Vestas, Suzlon e IMPSA (Barbará 2009). El parque eólico más grande se ubica en el municipio de Osório en Brasil, incluye los proyectos Sangradouro, Osório y Dos Indios; ${ }^{6}$ las desarrolladoras que los operan son las españolas, Enerfin y Enervento con un $90 \%$ de participación (Mendoza \& Pérez 2010).

Es importante resaltar que la implementación de proyectos con participación extranjera requiere cambios en las legislaciones nacionales. $\mathrm{Si}$ bien, los gobiernos latinoamericanos crean programas y políticas que incluyen la agenda verde, se presenta cierto nivel de rechazo y

${ }^{5}$ El Fondo para el Medio Ambiente Global y el Banco Mundial son algunos de los organismos internacionales que ofrecen apoyos económicos o de inversión para que las empresas realicen sus proyectos eólicos.

${ }^{6}$ Todos suman un potencial de producción de energía de $150 \mathrm{mw}$. 
Ambiente y Sostenibilidad 2016 (6): 55-63

Revista del Doctorado Interinstitucional en Ciencias Ambientales

ISSN: 2339-3122

Digital

resistencia social a dichos megaproyectos, fenómeno que debe considerarse en el análisis académico y en la formulación de planes y programas gubernamentales.

¿Cuáles son los factores que han generado esta oposición? Un elemento a considerar es la percepción ciudadana, es decir, los habitantes y afectados consideran que los gobiernos nacionales intervienen como mediadores $y$ facilitadores de las transnacionales. Y esta percepción se vuelve certera cuando los gobiernos en algunos casos expropian las tierras y otorgan permisos para la explotación de los recursos naturales, legitimando el despojo de los territorios, y por ende, las violaciones a los Derechos Humanos y laborales.

\section{Proyectos eólicos en México}

México se destaca de otros países latinoamericanos porque cuenta con un gran potencial para la generación de energía eólica. Las zonas más propicias para aplicar este tipo de proyectos son las penínsulas de Baja California y Yucatán, la región central de Zacatecas, Hidalgo, Veracruz, Sinaloa, Chihuahua, Sonora, Quintana Roo y las costas del pacífico. ${ }^{7}$ Hasta el momento se ha construido un parque en el poblado Guerrero Negro en Baja California Sur, ${ }^{8}$ y en la costa Chiapaneca.

Otras zonas de posible inversión son la Isla Holbox en Quintana Roo, donde empresas italianas están contemplando invertir. La empresa Econergy pretende instalar aerogeneradores en Santa Catarina, Nuevo León. También se tiene planeado el Parque eólico Los Vergeles en el municipio de San Fernando en Tamaulipas. Pese a la existencia de todas esas opciones, fue en el Istmo de Tehuantepec donde se instalaron por primera vez en el siglo XX las transnacionales.

\section{EL CORREDOR EÓLICO EN EL ISTMO DE TEHUANTEPEC}

Esta región es la más importante de México y América Latina en cuanto a producción de energía eólica. Por sus condiciones geográficas y climáticas ${ }^{9}$ se impulsó en 1994 el

\footnotetext{
${ }^{7}$ La Rumorosa, Sierra Juárez y sierra San Pedro Mártir en Baja California. Cabo Catoche en Yucatán, México.

8 La empresa Fuerza Eólica tiene permisos de construcción en Baja California, México.

9 El Istmo de Tehuantepec tienen amplias extensiones de llanuras que posibilitan que los vientos transiten libremente y alcancen velocidades de hasta ciento cincuenta kilómetros por hora.
}

proyecto piloto La Venta I. ${ }^{10}$ A partir de esta década, la zona se convierte en un codiciado botín por su alta rentabilidad, donde confluyen transnacionales españolas que aprovechan la potencia del viento y cuentan con una mayor inversión en la zona, algunas son: Unión Fenosa, Iberdrola, Preneal, Elioatec, Edf Energies Nouvelles-Mitsui, Gamesa. También hay capitales franceses, italianos y suecos. Quiénes transportan lo insumos tecnológicos para la construcción y operación de las centrales eólicas desde Europa al puerto de Salina Cruz Oaxaca, ubicado en el océano pacífico mexicano.

Estas empresas necesitaban grandes extensiones de tierras ejidales y el otorgamiento de permisos por parte de las autoridades municipales, estatales y federales. En el año 2000 iniciaron las pláticas con los ejidatarios y dos años después inició la construcción de centrales eólicas en los pueblos La Venta y La Ventosa, agencias municipales de Juchitán, Oaxaca.

La implementación de dicho proyecto y el acceso a las tierras ejidales fue posible, debido a la reforma agraria de 1992 derivada del modelo económico neoliberal, que modificó el artículo 27 de la Constitución Política de los Estados Unidos Mexicanos. Como parte de la reforma se instrumentó el Programa de Certificación de Derechos Ejidales y Titulación de Solares (PROCEDE), que tiene como objetivo promover el mercado de tierras para la renta, venta y compra. Con estas transformaciones en la legislación, los ejidatarios pueden firmar convenios con empresa y ceder sus derechos por treinta años, con posibilidad de renovación.

El desarrollo de los proyectos eólicos involucra varios tipos de convenios o contratos por arrendamiento, usufructo y compra-venta de tierras entre empresas y ejidatarios. Sin embargo, la modalidad aplicada en el Istmo de Tehuantepec es el de arrendamiento, y ello responde la facilidad de las empresas para mover sus capitales a cualquier punto del planeta, a la imposición del tipo de negociación y del monto a pagar a cada parte involucrada.

Una muestra de ello sucede desde el año 2000 a partir del cual muchos ejidatarios llevan realizando contratos de arrendamiento con las empresas que especificaban pagos muy bajos por la ocupación de sus tierras. En otras regiones del mundo ${ }^{11}$ donde se construyeron parques eólicos, se han desarrollado por lo menos dos tipos de arrendamiento: por cuota fija o por regalías. En la primera, el monto se fija por el

\footnotetext{
10 Proyecto impulsado por la Comisión Federal de Electricidad (CFE) y la empresa Deproe Energía del Istmo, que instalaron siete aerogeneradores en terrenos ejidales de La Ventosa, como parte del proyecto piloto.

${ }_{11}$ Por ejemplo en Estados Unidos, Alemania y España se han realizado contratos por cuota fija y regalías.
} 
número de turbinas o por unidad de tierras. En la segunda, se paga a los propietarios un porcentaje de los ingresos anuales por la producción. Esta opción implica transparentar las ganancias y disminuir los ingresos de las empresas. En algunos países las regalías oscilan entre dos o tres por ciento. En el Istmo se ha impuesto el de cuota fija.

Las negociaciones para decidir los montos económicos tardan meses, aunque al final son las empresas quienes los imponen. También protegen sus proyectos de cualquier desarrollo futuro que genere un impacto sobre los aerogeneradores. Celebran con los ejidatarios contratos por derechos de viento, donde se prohíbe cualquier construcción dentro de la central, que pudiera impedir el paso del viento en la zona donde se ubican los aerogeneradores. Además firman contratos para reservar tierras donde posteriormente se instalarán más eólicos.

En la mayoría de los casos, los ejidatarios y autoridades comunitarias carecen de información necesaria para tomar decisiones sobre la aceptación o no de parques, y negociar un mejor monto de arrendamiento con las empresas. Teóricamente, en la fase previa a la implementación, los gobiernos federal y estatal debieron informar sobre los contratos, procedimientos e impactos del megaproyecto. Sin embargo, los ejidatarios aseguran que en ningún momento se les proporcionó información detallada de las condiciones legales, las ventajas y desventajas de firmar los contratos.

La falta de información y el soborno a las autoridades ejidales, ahondó las divisiones y pugnas internas entre ejidatarios. Ello se refleja en el momento de decidir si las tierras de uso común deben rentarse. Son las asambleas ejidales de cada población, quiénes toman esas decisiones y eligen que obra pública debe construir la empresa. En otros casos, las autoridades ejidales han firmado los contratos a espaldas de la asamblea.

Otros actores que han tenido participación en las negociaciones son los partidos políticos y las dependencias de gobierno como la Procuraduría Agraria, la Secretaría de la Reforma Agraria, la Comisión Federal de Electricidad y la Secretaría de Energía, quienes han facilitado el trámite a las empresas y firmado como testigos en los contratos y convenios. Todo ello ha dejado un mal sabor de boca entre los ejidatarios.

Las empresas planean que a mediano plazo el corredor eólico se amplíe sobre terrenos ejidales y comunales de poblaciones indígenas y mestizas, donde ya se están firmando contratos de arrendamiento; además de Juchitán, Unión Hidalgo y Santo Domingo Ingenio que han sido afectadas. El megaproyecto contempla más de 120 mil hectáreas, incluye los municipios de Ixtepec, Ixtaltepec, San Francisco del Mar, San Mateo del Mar, San Dionisio del Mar, Chicapa de Castro, San Miguel Chimalapa, San Pedro Comitancillo y El Espinal.

Cabe destacar que las transnacionales productoras de energía operan en México a través de sus empresas filiales, de ahí que sea difícil rastrear el origen de la inversión, aunado a la falta de transparencia en la información por parte del gobierno federal y de las empresas. La participación de distintas compañías en la cadena productiva también genera confusión. A continuación se mencionan algunos parques que están operando:

> Central Eólica Santo Domingo, instalada en Unión Hidalgo, pertenece a la empresa Eólica del Pacífico S.A.P.I. de C.V.

$>$ Central Eólica Bii Stinu instalada en El Espinal (Juchitán), de la empresa Eoliatecm del Istmo.

$>$ Central Eólica Piedra Larga Etapa II, instalada en Unión Hidalgo.

\section{Los efectos sociales, ambientales, agrarios y económicos}

En los primeros años de implementación de los parques eólicos era difícil medir las consecuencias sociales, agrarias, ambientales, económicas y políticas. Sin embargo, una mirada en retrospectiva permite esbozar que la región se ha convertido en un caldo de cultivo para el descontento y la resistencia social. Fenómenos que tienen sus cimientos en la particular historia de lucha que han protagonizado los pueblos zapotecos y huaves, desde tiempos inmemoriales. El mayor agravio social surge por los mecanismos que han utilizado las compañías para conseguir los contratos, y el papel que han jugado los partidos políticos y los gobiernos en sus tres niveles: local, estatal y federal.

Desde una perspectiva socioantropológica los efectos sociales que hemos detectado en el Istmo de Tehuantepec a partir de la instalación de los eólicos son:

- La falta de consultas ciudadanas y públicas, no permiten que el proyecto tenga legitimidad entre la población local y regional.

- Las empresas no han pagado un precio justo por la renta de tierras.

- Los representantes de las empresas cooptan a personajes claves de las comunidades, convenciéndolos $\mathrm{u}$ obligándolos a firmar contratos de arrendamiento a espaldas de las asambleas ejidales, provocando división entre los ejidatarios. 
Ambiente y Sostenibilidad 2016 (6): 55-63

Revista del Doctorado Interinstitucional en Ciencias Ambientales

ISSN: 2339-3122

Digital

- Se han girado órdenes de aprehensión contra algunos ejidatarios que se oponen al proyecto.

- Aumento de la migración.

- Se han trastocado viviendas, zonas arqueológicas y lugares sagrados.

- Los trabajadores no tienen derechos laborales, contratos permanentes y servicios de salud.

- No existe un desarrollo comunitario.

Con respecto a los efectos ambientales hallamos los siguientes:

- Transformación del paisaje.

- Desaparición de cerros, lagunas, lagos y ríos.

- Contaminación de fuentes de agua.

- Apertura de brechas y con ello la desaparición de flora y fauna.

- Muerte de aves migratorias.

- Contaminación de la tierra debido a los desechos de combustible, particularmente de aceites.

Los efectos agrarios que observamos in situ son:

- Instrumentación del PROCEDE.

- Privatización de tierras.

- Cambio de uso de suelo.

- Cambio de tenencia de la tierra, de ejidal a propiedad privada.

- Las tierras están reguladas por la oferta y demanda que imponen las compañías.

En cuanto a los efectos económicos podemos afirmar lo siguiente:

- No hay generación de empleos a largo plazo.

- Han disminuido las actividades agrícolas y ganaderas, ya que las tierras están rentadas.

- Los terrenos dedicados al pastoreo del ganado vacuno están siendo ocupados por los aerogeneradores.

- En comparación con los proyectos implementados en Europa, los ejidatarios oaxaqueños reciben ínfimas utilidades.

Cabe agregar que una parte importante de la población local desaprueba los proyectos, señala que el Estado ha fungido como un facilitador de las transnacionales, violando los derechos humanos, laborales y de los pueblos indígenas. Ante la falta de información, la pobreza y la ignorancia de los ejidatarios, consideramos que las empresas han negociado contratos desventajosos de arrendamiento.

En un caso relevante, cuando se construyó el primer parque La Venta I, los compromisos de la Comisión Federal de Electricidad (CFE) y la empresa fueron la pavimentación de calles, abastecimiento de electricidad y agua potable a las comunidades. A cambio, la asamblea ejidal permitió la instalación de siete aerogeneradores. Sin embargo, no cumplieron, y cuando los ejidatarios exigieron cuentas claras, manifestaron que el proyecto piloto operaba con números rojos.

Otro caso importante de acción colectiva se suscitó en los últimos meses del año 2014, cuando la Empresa Energía Eólica Mareña, S. A. de C.V. inició las obras para construir el parque Mareña Renovable en San Dionisio del Mar. A pesar de que contaba con permisos 12 del Instituto Estatal de Ecología y Desarrollo Sustentable para abrir un camino interno al parque, en la zona de Cabo de Santa Teresa entre la Laguna Superior e Inferior, los indígenas huaves se opusieron y obligaron a la empresa a suspender la construcción. A partir de ese momento, comenzaron pláticas con el gobierno estatal y los representantes de las transnacionales.

\section{Mecanismos para la acción colectiva}

La pugna política y la consecuente división en los ejidos de la región istmeña han favorecido enormemente la instrumentación del proyecto eólico. Además hay opiniones y posturas encontradas. Por un lado, están los que se oponen definitivamente al corredor eólico, por los irreversibles daños ambientales y los escasos beneficios que trae a los habitantes locales. Por el otro, están quienes han firmado los contratos porque consideran que la instalación de aerogeneradores les proporciona un ingreso permanente, ante la falta de apoyos para cultivar la tierra y la poca oferta laboral en la región. También están los que no han firmado contratos hasta que las empresas aumenten la oferta por el alquiler de las tierras.

No obstante, la estrategia empresarial se ha centrado en la cooptación de autoridades ejidales y representantes de partidos políticos con resultados a su favor, debido a las cuantiosas ganancias que reciben. Desde que inició la construcción del corredor eólico, los ejidatarios enfrentaron ofertas engañosas de la Comisión Federal de Electricidad y

${ }^{12}$ En la página electrónica del Instituto Estatal de Ecología y Desarrollo Sustentable aparece un permiso para esa empresa, fechada en el año 2011. 
los representantes de las transnacionales. La Secretaría de la Reforma Agraria y la Procuraduría Agraria, han fungido como dependencias testigo en los convenios y contratos. Las tres les han negado a los ejidatarios copias de las actas de asamblea y de convenios firmados entre las autoridades ejidales y las empresas.

No está de más señalar que algunos líderes y representantes de los partidos políticos han designado estratégicamente a comisariados ejidales y agentes municipales, utilizando el capital político que tienen en las comunidades. También han ejercido presión sobre éstos para que otorguen los permisos o firmen convenios con las empresas.

Tras la experiencia que vivieron los ejidatarios de La Venta y La Ventosa. Crearon redes con otras comunidades que serían impactadas. Con el apoyo de Organizaciones No Gubernamentales han realizado movilizaciones, protestas, encuentros, foros de discusión, donde han participado representantes de cincuenta y nueve poblaciones indígenas del Istmo de Tehuantepec, entre ellos mixes, zapotecas, huaves, chontales y zoques; organizaciones ambientalistas y de derechos humanos nacionales e internacionales. En los foros han analizado los impactos de los proyectos, afianzado mecanismos de lucha que los han ido fortaleciendo.

Se han conformado frentes y asambleas de pueblos, como el Grupo Solidario del ejido La Venta. Han interpuesto demandas contra la CFE y amparos para anular los contratos de arrendamiento con algunas empresas. Los elementos que han dado cohesión al movimiento contra los eólicos guardan relación con la concepción, uso y apropiación del espacio de los pueblos indígenas en México, para quienes el territorio se convierte en un emblema de su identidad.

Todo este descontento organizado ha logrado cristalizar las demandas de los pueblos originarios y de la sociedad civil afectada, las cuales se muestran a continuación:

- Las empresas deben elevar los pagos o pagar el dos por ciento del valor de la electricidad generada anualmente y repartir las utilidades. Deben incluir a los ejidatarios como socios.

- Las empresas deben capacitar y emplear de manera permanente a los hijos de los ejidatarios.

- Los ejidatarios exigen un monto mayor por la reserva de tierras.

- El gobierno debe consultar a los pueblos indígenas y a la población en general antes de implementar cualquier proyecto.

- El gobierno y las empresas deben comprometerse a otorgar la información necesaria a la población.
- Parte de la energía producida debe abastecer a las poblaciones afectadas.

- El gobierno y las empresas deben asegurar el respeto a la cultura, la organización comunitaria y las decisiones de los pueblos.

- Las empresas deben mejorar las condiciones de renta de tierras, a través de contratos justos y claros.

- El gobierno debe realizar los estudios de impacto ambiental.

\section{REFLEXIONES FINALES}

Los factores geográficos, climáticos y la riqueza ambiental y cultural que alberga el Istmo, lo convierten en una región estratégica para cualquier tipo de proyecto. Los antecedentes históricos muestran que no es la primera vez que se convierte en blanco de múltiples propósitos. A más de quince años de la implementación del corredor eólico, la renta de terrenos ejidales y comunales se ha consolidado como un mecanismo que utilizan las empresas para acaparar grandes extensiones. Tierras que durante décadas fueron utilizadas para la siembra de maíz, ajonjolí, sorgo, cacahuate y caña dentro de la zona del distrito de riego 19. Si bien no hay un cambio formal en la tenencia, la cesión de los derechos ejidales a través de contratos con las empresas transnacionales ha generado una forma de privatización de las tierras y de los recursos naturales. Ante este escenario de despojo, los indígenas zapotecos y huaves, han creado estrategias de resistencia cimentadas en su identidad.

A raíz de la implementación del modelo neoliberal en 1982, el gobierno mexicano ha dejado de apoyar al campo mexicano, disminuyendo las oportunidades laborales y orillando a los campesinos a rentar sus tierras para que se instalen los aerogeneradores. El corredor eólico está en expansión y se planea que ocupará 120 mil hectáreas; afectando cultivos, ríos, cerros y viviendas. Las transnacionales sobornan a los gobiernos con el fin de obtener todas las facilidades normativas para invertir $\mathrm{y}$ poner en marcha sus proyectos de inversión. En este sentido, el Estado mexicano no ha cumplido su papel de salvaguarda de los derechos humanos, civiles y laborales de sus ciudadanos.

Las empresas recurren al concepto de créditos de carbono, formalizado por el Protocolo de Kyoto, que consiste en vender a un precio más elevado la energía, argumentando que se obtiene de manera sustentable. La ganancia va directamente a las transnacionales y no a los pobladores locales. Por el tipo de producción, venta y administración de la energía, podemos señalar que se ha privatizado este servicio a costa de la ocupación desigual del territorio itsmeño. 
Ambiente y Sostenibilidad 2016 (6): 55-63

Revista del Doctorado Interinstitucional en Ciencias Ambientales

ISSN: 2339-3122

Digital

\section{REFERENCIAS}

BARBARÁ, L. 2009. El mercado de la energía eólica en México. Instituto Español de Comercio Exterior, España. 71 pp.

MENDOZA, E. \& PÉREZ, V. 2010. Energías renovables y movimientos sociales en América Latina. Estudios Internacionales. Universidad de Chile. 165: 109-128.

PERROT, M. D. 1991. Les empêcheurs de développer en rond. Etnhie, París.

RAFFESTIN, C. 1979. Pour une geographie du pouvoir. Librairies Techniques, Paris. 190 pp.

SANTOS, M. 2008. Por uma geografía nova. Editora da Universidade de São Paulo, Brasil. 257 pp.

SCOTT, J. 2000. Los dominados y el arte de la resistencia. Discursos ocultos. Era, México. 314 pp. 